\title{
Newborn sex-specific transcriptome signatures and gestational exposure to fine particles: findings from the ENVIRONAGE birth cohort
}

\author{
Ellen Winckelmans ${ }^{1}$, Karen Vrijens ${ }^{1}$, Maria Tsamou' ${ }^{1}$ Bram G. Janssen ${ }^{1}$, Nelly D. Saenen ${ }^{1}$, Harry A. Roels ${ }^{1,2}$, \\ Jos Kleinjans ${ }^{3}$, Wouter Lefebvre ${ }^{4}$, Charlotte Vanpoucke ${ }^{5}$, Theo M. de Kok ${ }^{3}$ and Tim S. Nawrot ${ }^{1,6^{*}}$
}

\begin{abstract}
Background: Air pollution exposure during pregnancy has been associated with adverse birth outcomes and health problems later in life. We investigated sex-specific transcriptomic responses to gestational long- and shortterm exposure to particulate matter with a diameter $<2.5 \mu \mathrm{m}\left(\mathrm{PM}_{2.5}\right)$ in order to elucidate potential underlying mechanisms of action.

Methods: Whole genome gene expression was investigated in cord blood of 142 mother-newborn pairs that were enrolled in the ENVIRONAGE birth cohort. Daily PM PM.5 $_{2}$ exposure levels were calculated for each mother's home address using a spatial-temporal interpolation model in combination with a dispersion model to estimate both long- (annual average before delivery) and short- (last month of pregnancy) term exposure. We explored the association between gene expression levels and $\mathrm{PM}_{2.5}$ exposure, and identified modulated pathways by overrepresentation analysis and gene set enrichment analysis.

Results: Some processes were altered in both sexes for long- (e.g. DNA damage) or short-term exposure (e.g. olfactory signaling). For long-term exposure in boys neurodevelopment and RhoA pathways were modulated, while in girls defensin expression was down-regulated. For short-term exposure we identified pathways related to synaptic transmission and mitochondrial function (boys) and immune response (girls).

Conclusions: This is the first whole genome gene expression study in cord blood to identify sex-specific pathways altered by $\mathrm{PM}_{2.5}$. The identified transcriptome pathways could provide new molecular insights as to the interaction pattern of early life $\mathrm{PM}_{2.5}$ exposure with the biological development of the fetus.
\end{abstract}

Keywords: Ambient air pollution, Particulate matter, Microarray analysis, Fetal, Sex

\section{Background}

Changes in the transcriptome biology during fetal development can contribute to disease susceptibility. The fetal developmental period is known to be highly sensitive to environmental stressors causing alterations at different omic levels which may result in increased risk of disease in adulthood [1-3]. It has been hypothesized that specific

\footnotetext{
* Correspondence: tim.nawrot@uhasselt.be

${ }^{1}$ Centre for Environmental Sciences, Hasselt University, Agoralaan gebouw D,

B-3590 Diepenbeek, Belgium

${ }^{6}$ Department of Public Health \& Primary Care, Leuven University,

Kapucijnenvoer 35, 3000 Leuven, Belgium

Full list of author information is available at the end of the article
}

transcriptome profiles in response to gestational exposure to fine particulate matter (PM) may not only act as signatures of exposure but could also be potentially prognostic for exposure-related health outcomes later in life.

Several observational studies corroborated the relationship between PM air pollution and adverse birth outcomes, such as decreased fetal growth [4-6] and preterm birth $[7,8]$. Furthermore, perinatal physiological parameters like newborn systolic blood pressure were found to be associated with PM exposure during gestation [9]. Gestational air pollution exposure may affect the fetus in two different ways: 1) indirectly, 
through mediation by inflammatory effects on the mother's cardiorespiratory system and 2) directly, after translocation of (ultra)fine particles via the mother's bloodstream to the placenta. Wick et al. demonstrated in an ex vivo human placental perfusion model that polystyrene particles with a diameter up to $240 \mathrm{~nm}$ are able to cross the placental barrier [10].

There is suggestive evidence that prenatal air pollution exposure may be linked to various adverse effects later in life such as cognitive and behavioral changes [11, 12], cancer $[13,14]$, and respiratory ailments $[15,16]$. In addition, some studies reported sex differences in air pollution-related adverse health effects [17, 18]. Penaloza and colleagues [19] showed that sex-specific effects of prenatal exposure to environmental stressors are not only attributed to hormonal but also to chromosomal differences. Another study reported sex-specific associations between persistent organic pollutants and cord sex hormones [20].

PM air pollution is an omnipresent environmental risk factor for public health in large areas of the world, however, the impact of gestational exposure to PM air pollution on fetal transcriptome profiles has not been assessed so far. In order to elucidate potential molecular mechanisms underlying prenatal $\mathrm{PM}_{2.5}$-induced adverse health effects, we investigated sex-specific transcriptomic responses in cord blood as part of the early life exposome in the framework of the ENVIRONAGE birth cohort.

\section{Methods}

\section{Study population}

Mother-child pairs were enrolled in the on-going ENVIRONAGE birth cohort (ENVIRonmental influence $O N$ early AGEing) following procedures previously approved by the Ethical Committee of Hasselt University and the East-Limburg Hospital (09/080 U;B37120107805) [21], and complies with the Helsinki declaration. All participating mothers provided written informed consent. Cord blood samples were collected along with perinatal parameters such as birth date, gestational age, newborn's sex, birth weight and length. The mothers completed study questionnaires in the post-delivery ward to provide detailed information on maternal age, pre-gestational body mass index (BMI), maternal education, smoking status, alcohol consumption, place of residence, parity, and ethnicity of the newborn. Former-smokers were defined as those who had quit smoking before pregnancy. Smokers were those who continued smoking during pregnancy. Based on the native country of the newborn's grandparents we classified his/her ethnicity as European-Caucasian when two or more grandparents were European, or as non-European when at least three grandparents were of non-European origin. We asked the mothers whether they consumed alcohol during pregnancy. Maternal education was coded as "low" (no diploma or primary school), "medium" (high school) or "high" (college or university degree).

The ENVIRONAGE birth cohort had an overall participation rate of $61 \%$. The current study is based on a representative subgroup of the ENVIRONAGE birth cohort including 150 newborns recruited from South-EastLimburg Hospital in Genk (Belgium) born between Friday $1200 \mathrm{~h}$ and Monday $0700 \mathrm{~h}$ from March 20th 2010 until March 9th 2014. The general characteristics of the mother-child pairs did not differ from all births in Flanders as to maternal age, education, parity, sex, ethnicity, and birth weight (See Additional file 1: Table S1). Quality control of microarray data resulted in exclusion of four newborns. Of the remaining 146 newborns, we excluded four newborns for whom no prenatal exposure (lived outside the study area) were available. This resulted in a final sample of 142 mother-child pairs.

\section{Ambient $\mathrm{PM}_{2.5}$ exposure assessment}

For each mother's residential address, $\mathrm{PM}_{2.5}$ was calculated using a spatial temporal interpolation method (Kriging) taking into account land cover data obtained from satellite images (CORINE land cover data set) for interpolating the pollution data collected in the official fixed-site monitoring network in combination with a dispersion model (IFDM) using emissions from line sources and point sources [22-24]. This model chain provides daily $\mathrm{PM}_{2.5}$ values on a high resolution receptor grid. Overall, model performance was evaluated by leave-oneout cross-validation including 34 monitoring points for $\mathrm{PM}_{2.5}$. In our study area, the interpolation tool explained more than $80 \%$ of the temporal and spatial variability [24]. We defined two exposure windows of interest i.e. long-term (annual average before delivery) and shortterm (last month of pregnancy) exposure. Annual averages before delivery were preferred to gestational exposure since annual averages are independent of season of blood sampling, an important predictor of gene expression [25]. Moreover, maternal $\mathrm{PM}_{2.5}$ exposure during the 3 months before conception may induce maternal changes that may indirectly affect conception and the fetus and is thus included in annual averages. One month was taken as a period reflecting short-term exposure. Complete information was obtained for the residential address during and before pregnancy. For those who moved during pregnancy $(n=19 ; 13.4 \%)$, we calculated the exposure allowing for the changes in address during this period.

Meteorological data including mean daily air temperature and relative humidity were measured at the federal official station and provided by the Belgian Royal Meteorological Institute (Brussels, Belgium). Apparent temperature was averaged over one week before delivery and categorized based on the 25th, 50th and 75th percentiles. 


\section{RNA isolation}

Total RNA was isolated from whole blood collected in Tempus tubes (ThermoFisher Scientific, Waltham, MA, USA) using the Tempus Spin RNA Isolation kit (Life Technologies, Paisley, UK) according to the manufacturer's instructions. RNA yields were determined using the NanoDrop Spectrophotometer (Isogen Life Sciences, De Meern, the Netherlands) and the quality was checked on an Agilent 2100 Bioanalyzer (Agilent Technologies, Amstelveen, the Netherlands). Samples with RNA Integrity Number below 6 were excluded from further analysis. Samples were stored at $-80{ }^{\circ} \mathrm{C}$ until further processing.

\section{Microarray preparation, hybridization and preprocessing} An aliquot of $0.2 \mu \mathrm{g}$ total RNA was reverse-transcribed into cDNA, labeled with cyanine-3 following the Agilent one-color Quick-Amp labeling protocol (Agilent Technologies) and hybridized onto Agilent Whole Human Genome $8 \times 60 \mathrm{~K}$ microarrays. Microarray signals were detected using the Agilent DNA G2505C Microarray Scanner (Agilent Technologies). Scan images were converted into TXT files using the Agilent Feature Extraction Software (Version 10.7.3.1, Agilent Technologies, Amstelveen, The Netherlands), which were imported in R 2.15.3 (http://www.r-project.org). An in-house developed quality control pipeline in $\mathrm{R}$ software was used to preprocess raw data as follows: local background correction, omission of controls, flagging of bad spots and spots with too low intensity, $\log _{2}$ transformation and quantile normalization using arrayQC. The R-scripts of the quality control pipeline and more detailed information on the flagging can be found at https:/github.com/ BiGCAT-UM/arrayQC_Module. Further preprocessing included removal of genes with more than $30 \%$ flagged data, merging of replicates based on the median, imputation of missing values by means of K-nearest neighbor imputation $(\mathrm{K}=15)$ and correction for batch effects using an empirical Bayes method [26]. For genes represented by multiple probes, only the probe with the largest interquartile range was considered. The final dataset used for statistical analyses contained 16,844 genes.

\section{Data analysis}

To study alterations in gene expression in association with long-term (one year before delivery) and shortterm (one month before delivery) exposure, multivariable-adjusted linear regression was performed while accounting for gestational age, season of conception, averaged apparent temperature over the last week of pregnancy (categories: <4.4, 4.4-7.9, 7.9-14.1, >14.1 $\mathrm{C}^{\circ}$ ), parity (first, second, higher-order birth), maternal age, smoking status (never, past or current smoker), maternal education (lower secondary or less, higher secondary, higher education), ethnicity of the grandparents (European-Caucasian, yes or no), gestational age, pre-pregnancy BMI, newborn's sex, long- or short-term $\mathrm{PM}_{2.5}$ exposure, and the interaction term between newborn's sex and exposure. The interaction term was included in the models based on previous evidence suggesting differential responses between both sexes to environmental stressors during the perinatal period. Also at gene expression level, several animal studies [19, 27-30] and an epidemiological study of Hochstenbach and colleagues [2] observed sex-specific responses to prenatal environmental stress. For each sex, fold changes were calculated for an increase in long-term $\mathrm{PM}_{2.5}$ exposure of $5 \mu \mathrm{g} / \mathrm{m}^{3}$ and for an increase of $10 \mu \mathrm{g} / \mathrm{m}^{3}$ in short-term $\mathrm{PM}_{2.5}$ exposure. A $p$ value smaller than 0.05 was considered significant. A principal component analysis was performed based on the significant genes $(p$-value $<0.05)$ for long- and short-term exposure for both sexes. Partial correlation coefficients (R) were calculated between principal component scores and long- and short-term $\mathrm{PM}_{2.5}$ exposure.

In a sensitivity analysis, we additionally adjusted for white blood cell (WBC) counts and the percentage of neutrophils. However, due to blood clotting, data on these two variables were missing for 31 newborns. Normally, at birth the amount of WBCs ranges from 9 to $30 \times 10^{3} / \mu \mathrm{L}$. One newborn was excluded due to an outlying WBC count $\left(>35 \times 10^{3} / \mu \mathrm{L}\right)$. We assumed data is "at least missing at random". Single stochastic regression imputation was performed in SAS using the FCS statement in proc MI. For the WBC counts and percentage of neutrophils, we included in the imputation model the covariates of the main model and, respectively the top three significant genes related to WBC counts and neutrophil percentage resulting from a complete case analysis.

\section{Pathway analysis by ConsensusPathDB}

Genes significantly $(p<0.05)$ associated with $\mathrm{PM}_{2.5}$ exposure were uploaded into the Online Overrepresentation Analysis Tool ConsensusPathDB (http://consensuspathdb.org/) [31] of the Max Planck Institute for Molecular Genetics, to identify pathways associated with $\mathrm{PM}_{2.5}$ exposure. A $p$-value representing the pathway of smaller than 0.05 was considered significant.

\section{Gene set enrichment analysis}

The GSEA (Gene Set Enrichment Analysis) software tool (MSigDB, version 5.0) [32, 33] was used to find pathways significantly correlated with $\mathrm{PM}_{2.5}$ exposure. Genes were ranked by the $\log _{2}$-fold change. Subsequently, an enrichment score was calculated reflecting the degree a pathway is enriched by highly ranked genes. The statistical significance was estimated using a gene set permutation test with false discovery rate (FDR) correction for multiple hypothesis testing. 
Pathways with a q-value (FDR adjusted $p$-value) below 0.05 and $p$-value smaller than 0.005 were considered significant. Significant pathways were visualized using plug-in EnrichmentMap of cytoscape 3.2.0 software (http://cytoscape.org) [34]. An overlap coefficient of 0.5 was applied as similarity cutoff.

\section{Results}

Table 1 shows demographic characteristics and perinatal traits of the mother-child group $(n=142)$. Mean maternal age was 29.3 (range: 18-42) years and mean (SD) pregestational BMI was $24.2(4.6) \mathrm{kg} / \mathrm{m}^{2}$. Most women never smoked $(n=80)$, 36 women stopped smoking before pregnancy, whereas 26 mothers reported to continue smoking during pregnancy (on average 8.6 cigarettes/day). More than $80 \%$ of the mothers never used alcoholic beverages during pregnancy. The newborns, among them 76 girls (53.5\%), had a mean gestational age of 39.7 weeks (range, 35.9-41.1) and comprised 70 primiparous and 59 secundiparous newborns. About $90 \%$ of the newborns were Europeans of Caucasian ethnicity and their mean (SD) birth weight was 3454 (431) g. Maternal exposure to $\mathrm{PM}_{2.5}$ over one year (long-term) and one month (short-term) preceding delivery averaged 16.0 (range: 11.8-20.6) and 13.3 (range: $6.5-34.8) \mu \mathrm{g} / \mathrm{m}^{3}$ respectively.

A histogram of the percentage of genes associated with each of the covariates included in the model ( $p$-value $<0.05)$ is given in Additional file 1: Figure S1.

The effect of long-term gestational $\mathrm{PM}_{2.5}$ exposure (annual average before delivery) on gene expression in cord blood revealed major differences between girls and boys. A total of 1269 (7.5\%) genes showed a significant interaction between fine particle air pollution and the sex of the newborn. For girls and boys, this study identified respectively 724 and 1358 genes which were significantly associated with long-term gestational $\mathrm{PM}_{2.5}$ exposure. Among these genes, 75 were differentially expressed in both boys and girls (see Additional file 1: Table S2). Additional file 1: Table S3 represents the top ten significant genes for boys and girls separately and their fold changes for a $5 \mu \mathrm{g} / \mathrm{m}^{3}$ increment in $\mathrm{PM}_{2.5}$ exposure.

Additional file 1: Figure S2A and B show the association of the first and second principal component score with long-term $\mathrm{PM}_{2.5}$ exposure for girls and boys respectively. Both principal components were significantly associated with long-term $\mathrm{PM}_{2.5}$ exposure in both girls (PC1: $p$-value $<0.0001, R=0.51 ; \mathrm{PC} 2: p$-value $=0.03$, $R=-0.29)$ and boys (PC1: $p$-value $=0.004, R=-0.40$; PC2: $p$-value $<0.0001, R=-0.63)$.

To identify potential short-term exposure effects on gene expression, we analyzed the microarray data while using the mean $\mathrm{PM}_{2.5}$ exposure during the last month of pregnancy. We observed 432 (2.6\%) genes of which the
Table 1 Demographic characteristics of the study population and exposure $(n=142)$

\begin{tabular}{|c|c|}
\hline Characteristic & $\begin{array}{l}\text { Mean }(p 10, p 90) \\
\text { or } n(\%)\end{array}$ \\
\hline \multicolumn{2}{|l|}{ Mothers } \\
\hline Age, yrs & $29.3(24.0,34.0)$ \\
\hline Pre-gestational BMl, kg/m² & $24.2(19.5,30.5)$ \\
\hline \multicolumn{2}{|l|}{ Education } \\
\hline Low & $15(10.6 \%)$ \\
\hline Medium & $50(35.2 \%)$ \\
\hline High & $77(54.2 \%)$ \\
\hline \multicolumn{2}{|l|}{ Smoking status } \\
\hline Never-smoker & $80(56.3 \%)$ \\
\hline Former-smokers & $36(25.4 \%)$ \\
\hline Smokers & $26(18.3 \%)$ \\
\hline \multicolumn{2}{|l|}{ Alcohol consumption } \\
\hline No & $119(83.8 \%)$ \\
\hline Occasionally & $23(16.2 \%)$ \\
\hline \multicolumn{2}{|l|}{ Parity } \\
\hline 1 & $70(49.3 \%)$ \\
\hline 2 & $59(41.5 \%)$ \\
\hline$\geq 3$ & $13(9.2 \%)$ \\
\hline \multicolumn{2}{|l|}{ Newborns } \\
\hline \multicolumn{2}{|l|}{ Sex } \\
\hline Boys & $66(46.5 \%)$ \\
\hline \multicolumn{2}{|l|}{ Season at conception } \\
\hline Winter & $38(26.8 \%)$ \\
\hline Spring & $40(28.2 \%)$ \\
\hline Summer & $37(26.1 \%)$ \\
\hline Autumn & 27 (19.0\%) \\
\hline \multicolumn{2}{|l|}{ Ethnicity } \\
\hline European-Caucasian & $124(87.3 \%)$ \\
\hline Gestational age, wks & $39.7(38.3,41.1)$ \\
\hline Birth weight, g & $3454(2910,4045)$ \\
\hline \multicolumn{2}{|l|}{ Exposure } \\
\hline Long-term ${ }^{\mathrm{a}} \mathrm{PM}_{2.5}, \mu \mathrm{g} / \mathrm{m}^{3}$ & $16.0(13.9,18.3)$ \\
\hline Short-term ${ }^{\mathrm{b}} \mathrm{PM}_{2.5}, \mathrm{\mu g} / \mathrm{m}^{3}$ & $13.3(8.0,21.4)$ \\
\hline Weekly apparent temp, ${ }^{\circ} \mathrm{C}$ & $8.9(2.4,16.5)$ \\
\hline
\end{tabular}

expression in boys and girls was differentially affected by exposure. For girls and boys, we identified 507 and 1144 genes respectively which were significantly associated with the last month of gestational $\mathrm{PM}_{2.5}$ exposure. Of these, there were 55 significant genes in overlap between boys and girls (See Additional file 1: Table S4). The top ten significant genes for each sex are given in Additional file 1: Table S5. 
For boys, we found 180 genes significantly associated with both long- and short-term exposure, while 113 genes for girls.

Additional file 1: Figure S2C and D show the association of the first and second (third) principal component score with short-term $\mathrm{PM}_{2.5}$ exposure for girls and boys respectively. The first principal component was significantly associated with long-term $\mathrm{PM}_{2.5}$ exposure in both girls (PC1: $p$-value $=0.0005, R=0.43 ; \mathrm{PC} 2: p$-value $=0.20, R=0.17$ ) and boys (PC1: $p$-value $<0.0001, R=-0.58$; PC2: $p$-value $=0.28, R=0.16)$. For girls, the third principal component was significantly correlated with short-term $\mathrm{PM}_{2.5}$ exposure (PC3: $p$-value $=0.01, R=-0.31$ ) and is therefore given on the $y$-axis in Additional file 1: Figure S2C.

Newborn sex-specific $\mathrm{PM}_{2.5}$ associated effects were further explored with overrepresentation analyses. The top 15 significant pathways with at least 15 measured genes and a total gene size of at most 500 genes are represented for both sexes in Tables 2 and 3 for longand short-term $\mathrm{PM}_{2.5}$ exposure respectively. For each pathway, gene symbols and an indication of down- or up-regulation in association with $\mathrm{PM}_{2.5}$ exposure are given for the significant genes. For pathways with the same contributing genes, only the most significant pathway is shown.

For girls, "Generic Transcription Pathway" and "Defensins" were the top most significant pathways in relation to long-term $\mathrm{PM}_{2.5}$ exposure including 22\% and $79 \%$ down-regulated genes respectively (Table 2). Both $\alpha$ - and $\beta$-defensins, involved in host defense and chronic inflammatory responses, were deregulated by long-term $\mathrm{PM}_{2.5}$ exposure. Among the 11 measured genes specifically encoding defensin peptides, 9 were down-regulated. Other significant pathways were related to DNA damage response, cancer, signaling transduction, scavenging, and the extracellular matrix.

For boys, the "Tumor necrosis factor (TNF) receptor signaling pathway" was most significantly associated with long-term $\mathrm{PM}_{2.5}$ exposure (Table 2). Other top significant pathways were mostly involved in the immune response or were related to cancer or the nervous system. Longterm $\mathrm{PM}_{2.5}$ was associated with lower expression of various genes of the ephrin family [e.g. ephrins $(E P H)$ and EPH-related receptors $(E F N)]$ and members of the Roundabout (ROBO) family [e.g. $\mathrm{ROBO} 2$ and $\mathrm{ROBO} 3$ ].

For the pathways "Oncogene Induced Senescence", "TP53 Network", and "Bladder Cancer", we observed a down-regulation of tumor protein p53 (TP53) and an increase of Mouse double minute 2 homolog (MDM2) expression, an important inhibitor of TP53 transcriptional activation.

For girls, overrepresentation analysis for short-term $\mathrm{PM}_{2.5}$ exposure revealed pathways related to transcriptional regulation, immune response, embryonic development, cardiovascular system, and response to DNA damage (Table 3).

For boys, the top significant pathway for short-term $\mathrm{PM}_{2.5}$ exposure was "Lidocaine (Local Anaesthetic) Action Pathway" which contains gene encoding voltage-gated sodium channels in peripheral neurons (Table 3). Other significant pathways were "Hedgehog ligand biogenesis" important for embryonic development, "Tricarboxylic acid (TCA) cycle" responsible for energy production, and "Neuroactive ligand-receptor interaction - Homo sapiens (human)" including several neurotransmitter receptor encoding genes which are negatively associated with shortterm $\mathrm{PM}_{2.5}$ exposure.

Clusters of functional related pathways, modulated by long- and short-term $\mathrm{PM}_{2.5}$ exposure, are presented in Additional file 1: Figure S3 and S4 respectively. Each cluster is encircled and assigned a label. Tables 4 and 5 list the cluster labels and the corresponding individual pathways which were significantly up- or downregulated by longand short-term $\mathrm{PM}_{2.5}$ exposure respectively. Table 4 shows the GSEA results for long-term exposure in girls which were consistent with the overrepresentation analysis for 1) the pathways "Defensins" and "Extracellular matrix organization", which both were down-regulated, and for 2) the pathways related to Transcription-SMAD2, 3 , 4-TGF $\beta$ which were up-regulated. Additional pathways were related to the cell cycle ("FOXM1" and "Aurora B pathway") and pathways containing genes encoding histone peptides, ribosomal peptides, and olfactory receptors.

For boys, the top significant pathways modulated by long-term $\mathrm{PM}_{2.5}$ exposure were all up-regulated (Table 4) and were related with cell cycle, plasminogen activation system (UPA-UPAR pathway), execution phase of apoptosis, Ras homolog gene family member A (RhoA) pathway, and regulation of gene expression by histone deacetylase (HDAC) class III. The 18 "leading edge genes" of the RhoA pathway included among others DiaphanousRelated Formin 1 (DIAPH1), Rho-Associated Coiled-Coil Containing Protein Kinase 1 (ROCK1), and ROCK2 of which the gene products are effectors of RhoA. Two of these effectors, ROCK1 and DIAPH1 were significantly associated with long-term $\mathrm{PM}_{2.5}$ exposure. Plasminogen activation system was also $\mathrm{PM}_{2.5}$ sensitive in girls (Table 2).

For girls, GSEA results for short-term $\mathrm{PM}_{2.5}$ exposure revealed significantly up-regulated pathways related to ribosomes and significantly down-regulated pathways related to the Rho pathway and olfactory signaling (Table 5). As found before in girls for long-term exposure, both olfactory signaling and ribosome related pathways were also significantly associated with short-term $\mathrm{PM}_{2.5}$ exposure. The Rho pathway contained 12 "leading edge genes" including RHOA, DIAPH1, LIM domain kinase 1 (LIMK1), Cofilin 1 (CFL1), several members of the Rho guanine nucleotide exchange factors (ARHGEF) 


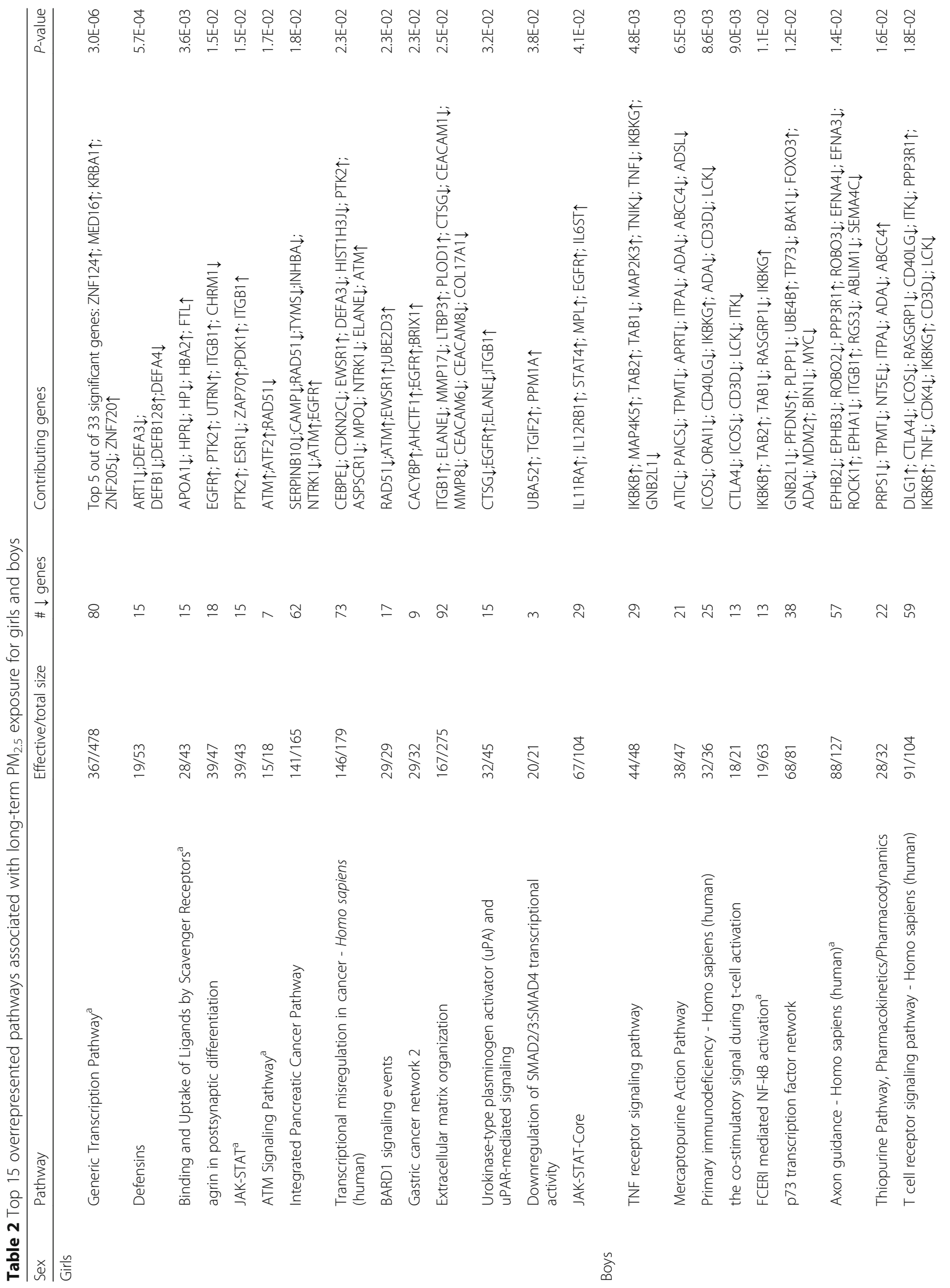




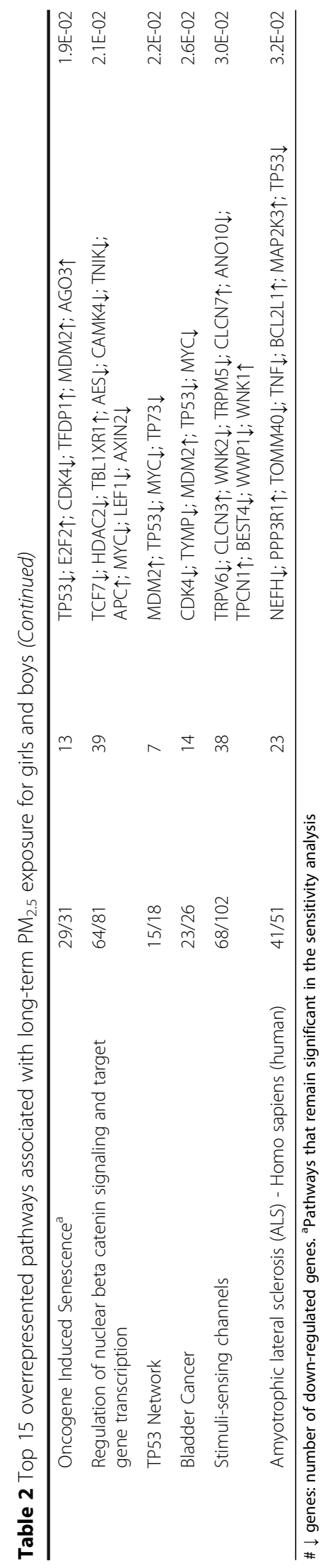




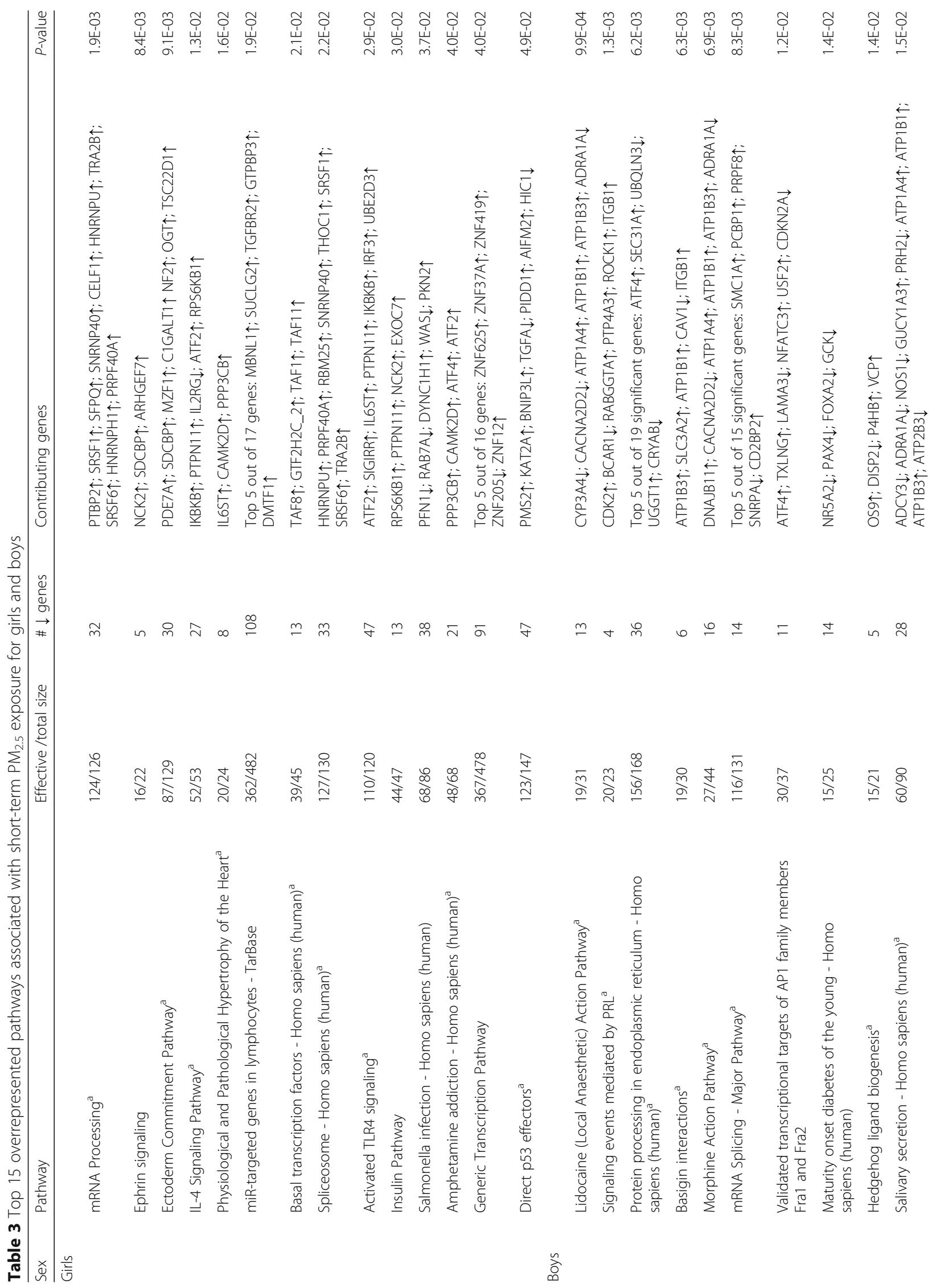




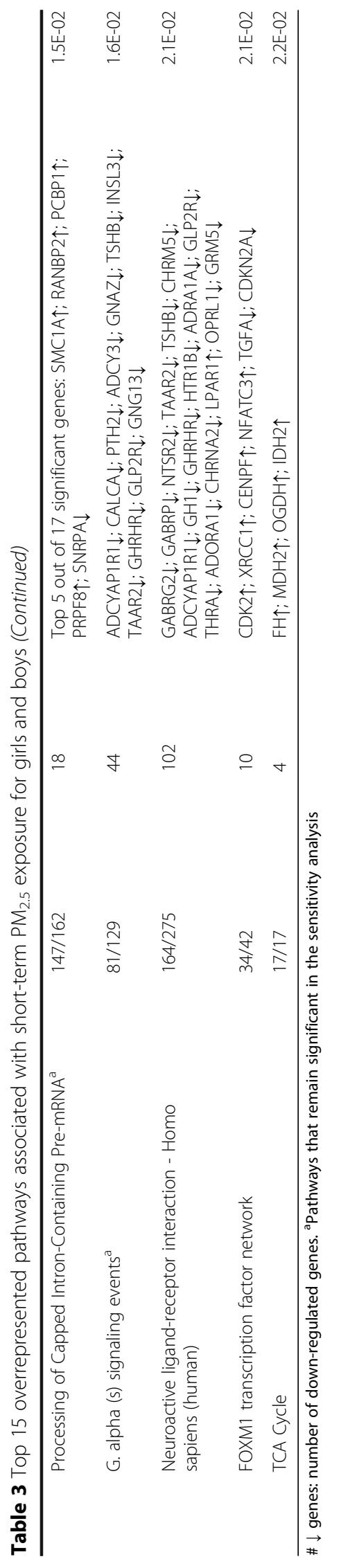


Table 4 Pathways modulated by long-term $\mathrm{PM}_{2.5}$ exposure for girls and boys resulting from GSEA

\begin{tabular}{|c|c|c|c|c|}
\hline Sex & Cluster label & Source: pathway & \# genes & Direction of regulation \\
\hline \multirow[t]{23}{*}{ Girls } & Aurora B pathway & PID: Aurora B pathway & 36 & DOWN \\
\hline & Core matrisome & Matrisome: Naba core matrisome & 142 & DOWN \\
\hline & Defensins & Reactome: defensins & 18 & DOWN \\
\hline & \multirow[t]{3}{*}{ Extracellular matrix organization } & & & DOWN \\
\hline & & Reactome: extracellular matrix organization & 49 & \\
\hline & & Reactome: degradation of the extracellular matrix & 18 & \\
\hline & FOXM1 pathway & PID: FOXM1 pathway & 32 & DOWN \\
\hline & \multirow[t]{4}{*}{ Histone related pathways } & & & DOWN \\
\hline & & Reactome: amyloids & 69 & DOWN \\
\hline & & Reactome: RNA polymerase I promotor opening & 54 & DOWN \\
\hline & & KEGG: systemic lupus erythematosus & 116 & DOWN \\
\hline & \multirow[t]{3}{*}{ Olfactory signaling } & & & DOWN \\
\hline & & KEGG: olfactory transduction & 124 & DOWN \\
\hline & & Reactome: olfactory signaling pathway & 95 & DOWN \\
\hline & Porphyrin metabolism & KEGG: porphyrin and chlorophyll metabolism & 25 & DOWN \\
\hline & \multirow[t]{4}{*}{ Ribosome related pathways } & & & UP \\
\hline & & Reactome: peptide chain elongation & 83 & \\
\hline & & KEGG: ribosome & 85 & \\
\hline & & $\begin{array}{l}\text { Reactome: nonsense mediated decay enhanced by } \\
\text { the exon junction complex }\end{array}$ & 104 & \\
\hline & \multirow[t]{4}{*}{ Transcription-SMAD2,3,4-TGF $\beta$ pathways } & & & UP \\
\hline & & Reactome: generic transcription pathway & 267 & \\
\hline & & $\begin{array}{l}\text { Reactome: downregulation of SMAD2, 3, SMAD4 } \\
\text { transcriptional activity }\end{array}$ & 18 & \\
\hline & & Reactome: signaling by TGF-beta receptor complex & 54 & \\
\hline \multirow[t]{8}{*}{ Boys } & Apoptotic execution & Reactome: apoptotic execution phase & 43 & UP \\
\hline & \multirow[t]{4}{*}{ Cell cycle } & & & UP \\
\hline & & Reactome: cell cycle mitotic & 290 & \\
\hline & & Reactome: mitotic prometaphase & 79 & \\
\hline & & Reactome: DNA replication & 176 & \\
\hline & HDAC class III & PID: HDAC class III pathway & 22 & UP \\
\hline & UPA-UPAR pathway & PID: UPA uPAR pathway & 30 & UP \\
\hline & RhoA pathway & PID: RhoA pathway & 37 & UP \\
\hline
\end{tabular}

For clusters containing more than 3 pathways, only the top 3 significant pathways are given.

\# gene: number of genes within a pathway. UPAR Urokinase-type plasminogen activator (uPA) receptor, HDAC histone deacetylase, FOXM1 forkhead box M1, RhoA Ras homolog gene family member A, PID Pathway Interaction Database, KEGG Kyoto Encyclopedia of Genes and Genomes

family, and genes encoding subunits of the Actin Related Protein 2/3 Complex. However, none of these genes were significantly associated with short-term $\mathrm{PM}_{2.5}$ exposure.

For boys, there were 132 significantly up-regulated and 11 down-regulated pathways by short-term $\mathrm{PM}_{2.5}$ exposure. Because of the large amount of significant pathways, Table 5 represents only the pathways with both $p$-value and q-value smaller than 0.005. Most of the significant pathways were up-regulated and linked to the cell cycle or ribosomes. Other up-regulated pathways were related to the TCA cycle and DNA damage response including "BRCA1 Associated RING Domain 1 (BARD1) pathway" and "Ataxia Telangiectasia Mutated (ATM) pathway". The 23 "leading edge genes" of the BARD1 pathway included among others BARD1, Breast Cancer 1 Early Onset (BRCA1), and ATM. Note that "BARD1 pathway" and "ATM pathway" were also significantly associated with long-term $\mathrm{PM}_{2.5}$ exposure in girls (Table 2). The RhoA pathway results were similar as those for long-term $\mathrm{PM}_{2.5}$ exposure. DIAPH1 and ROCK1 were both significantly associated with shortterm $\mathrm{PM}_{2.5}$ exposure and contributed to the "leading 
Table 5 Pathways modulated by short-term $\mathrm{PM}_{2.5}$ exposure for girls and boys resulting from GSEA

\begin{tabular}{|c|c|c|c|c|}
\hline Sex & Cluster label & Source: pathway & \# genes & Direction of regulation \\
\hline \multirow[t]{6}{*}{ Girls } & Olfactory signaling & Reactome: olfactory signaling pathway & 95 & DOWN \\
\hline & Rho pathway & BioCarta: Rho pathway & 28 & DOWN \\
\hline & Ribosome related pathways & & & UP \\
\hline & & $\begin{array}{l}\text { Reactome: nonsense mediated decay enhanced by the } \\
\text { exon junction complex }\end{array}$ & 104 & \\
\hline & & KEGG: ribosome & 85 & \\
\hline & & Reactome: 3' UTR mediated translational regulation & 102 & \\
\hline \multirow[t]{27}{*}{ Boys } & ATM pathway & PID: ATM pathway & 18 & UP \\
\hline & BARD1 pathway & PID: BARD1 pathway & 29 & UP \\
\hline & Cell Cycle & & & UP \\
\hline & & Reactome: DNA replication & 176 & \\
\hline & & Reactome: G2/M checkpoints & 37 & \\
\hline & & Reactome: cell cycle mitotic & 290 & \\
\hline & ETC-TCA cycle & & & UP \\
\hline & & Reactome: TCA cycle and respiratory electron transport & 113 & \\
\hline & & $\begin{array}{l}\text { Reactome: respiratory electron transport atp synthesis } \\
\text { by chemiosmotic coupling and heat production by } \\
\text { uncoupling proteins }\end{array}$ & 79 & \\
\hline & M-calpain pathway & BioCarta: M-calpain pathway & 21 & UP \\
\hline & Metabolism of mRNA and RNA & & & UP \\
\hline & & Reactome: metabolism of RNA & 249 & \\
\hline & & Reactome: metabolism of mRNA & 204 & \\
\hline & Myc pathway & PID: Myc activ pathway & 76 & UP \\
\hline & Olfactory signaling & & & DOWN \\
\hline & & KEGG: olfactory transduction & 124 & \\
\hline & & Reactome: olfactory signaling pathway & 95 & \\
\hline & mRNA processing & & & UP \\
\hline & & Reactome: processing of capped intron containing pre mRNA & 133 & UP \\
\hline & & Reactome: mRNA processing & 147 & \\
\hline & Response to elevated platelet cytosolic $\mathrm{CA}^{2+}$ & Reactome: response to elevated platelet cytosolic $\mathrm{CA}^{2+}$ & 66 & UP \\
\hline & Ribosome related pathways & & & UP \\
\hline & & Reactome: translation & 141 & \\
\hline & & $\begin{array}{l}\text { Reactome: SRP dependent cotranslational protein targeting } \\
\text { to membrane }\end{array}$ & 105 & \\
\hline & & Reactome: 3' UTR mediated translational regulation & 102 & \\
\hline & RhoA pathway & PID: RhoA pathway & 37 & UP \\
\hline & Splicesome & KEGG: spliceosome & 123 & UP \\
\hline
\end{tabular}

For clusters containing more than 3 pathways, only the top 3 significant pathways are given

\# genes: number of genes within a pathway. Rho Ras Homolog gene family, TCA tricarboxylic acid, ETC electron transport chain, ATM Ataxia Telangiectasia Mutated, BARD1 BRCA1 associated RING domain 1. Myc v-myc avian myelocytomatosis viral oncogene homolog, PID Pathway Interaction Database, KEGG Kyoto Encyclopedia of Genes and Genomes

edge genes". Down-regulated pathways were related to olfactory receptor signaling pathways.

It has been reported that air pollution exposure can induce changes in WBC counts in adults [35, 36], and changes in cord blood cell distribution might influence the overall blood transcriptome profile. However, in our newborn cohort, we did not find a significant association between $\mathrm{PM}_{2.5}$ exposure and WBC count and neutrophil percentage in cord blood. Nevertheless, in a sensitivity analysis we added WBC count and neutrophil percentage to the main model. For girls, 525 (72.5\%) of the significant genes in the main analysis remained significantly 
associated with long-term $\mathrm{PM}_{2.5}$ exposure after adjustment for WBC count and neutrophil percentage. Overrepresented pathways of the main analysis that remained significant in the sensitivity analysis are marked $\left({ }^{a}\right)$ (Table 2). For GSEA, pathways related to defensins, histones ("Amyloids"), extracellular matrix organization, and olfactory receptors remained in the top most significant pathways.

For boys, 773 (56.9\%) of the significant genes associated with long-term $\mathrm{PM}_{2.5}$ exposure in the main analysis remained significant after adjustment for WBC count and neutrophil percentage. GSEA confirmed our main findings with pathways related to the cell cycle (q-value $<0.25$ and $p$-value $<0.005)$ including "Mitotic M-M/G1 phases", "Cell cycle mitotic", and "Loss of Ninein-Like Protein (NLP) from mitotic centrosomes". For girls, 433 (85.4\%) genes which significantly correlated with short-term $\mathrm{PM}_{2.5}$ exposure in the main analysis were in overlap with the sensitivity analysis. Of the top 15 significant enriched pathways for short-term $\mathrm{PM}_{2.5}$ exposure in girls (Table 3), nine pathways remained significantly overrepresented in the sensitivity analysis. No significant up-regulated pathways resulted from GSEA, however, ribosome related pathways had the most significant positive association with shortterm $\mathrm{PM}_{2.5}$ exposure. Pathways related to olfactory signaling remained significantly down-regulated.

For boys, 1055 (92.2\%) of the significant genes in the main analysis remained significantly correlated with shortterm $\mathrm{PM}_{2.5}$ exposure in the sensitivity analysis. The most significant overrepresented pathway after adjustment for blood count was proteasome complex of which all ten contributing genes were up-regulated. Eight of these genes encoded proteasome subunits. Of the top 15 significant pathways in the main overrepresentation analysis, ten pathways remained significantly enriched in the sensitivity analysis (Table 3). GSEA revealed 134 significantly upregulated and 13 down-regulated pathways. All pathways shown in Table 5 remained significant except the "Mcalpain pathway".

\section{Discussion}

This is the first paper reporting neonate transcriptome signatures for long-term and short-term gestational exposure to PM. Although epidemiological studies are scarce, transcriptome alterations in early life may act in response to environmental exposures heralding adverse health outcomes later in life. At the gene level we observed in cord blood substantial differences in transcriptomic responses between newborn girls and boys in association with air pollution exposure during pregnancy. However, pathway analyses revealed alterations in the immune and DNA damage responses in both sexes for long-term exposure. Considering short-term exposure (last month of pregnancy), significant pathways were identified for both girls and boys which were related to olfactory receptors, ribosomes, and DNA damage. For long-term exposure, we also found sex-specific pathways including "axon guidance" and "RhoA pathway" for boys, while olfactory receptor, cell cycle, ribosomal, and defensin-related processes were girl-specific. Sex-specific pathways associated with short-term exposure in boys included processes involved in synaptic transmission ("neuroactive ligand-receptor interaction") and mitochondrial energy production, and for girls immune response pathways. Table 6 gives an overview of these biological processes altered by gestational PM exposure.

We suggest that the observed inverse association between gene expression of olfactory receptors could be an early marker of the effects of fine particle air pollution on the central nervous system. An association between air pollution exposure and olfactory dysfunction has been suggested to be involved in the development of various diseases such as Alzheimer and Parkinson's disease [37]. Importantly, the functional role of gene expression of olfactory receptors in blood parallels severity of head injury as indicated in patients suffering of traumatic brain injury [38].

Besides olfactory receptor signaling, we identified other neurological pathways affected by long- and short-term $\mathrm{PM}_{2.5}$ exposure in boys. Long-term exposure down-regulated the expression of ROBO, EPH and EFN members which are essential for axon guidance during neurodevelopment. Short-term $\mathrm{PM}_{2.5}$ exposure altered expression of "Neuroactive ligand-receptor interaction - Homo sapiens (human)" gene members including several types of neurotransmitter receptor encoding genes such as gamma-aminobutyric acid (GABA) receptors, cholinergic and glutamate receptors. Interestingly, all these contributing genes were negatively correlated with $\mathrm{PM}_{2.5}$ exposure. In mice, decreased expression of ionotropic glutamate receptor subunit in the hippocampus of offspring was shown following gestational exposure to benzo(a)pyrene [39]. In rats, exposure to cigarette smoke showed a dose-dependent decrease of GABA B receptor, 1 mRNA expression in the hippocampus [40]. Changes in neurotransmitter receptor expressions early in life are predictive for cognitive dysfunction and behavior deficits later in life [41].

In adults, the increased risk in lung cancer associated with ambient air pollution is suspected to be linked to genotoxic chemicals absorbed on PM, more specifically polycyclic aromatic hydrocarbons (PAH) [42], and toxic metals e.g. cadmium [43]. Fetuses are more susceptible to carcinogenic exposures due to their rapid cell proliferation and differentiation, greater absorption and retention, immature immune system, and decreased capacity of detoxification, DNA repair or apoptotic [44, 45]. Micronuclei, a validated biomarker of cancer risk, are extranuclear bodies 
Table 6 Overview of selected biological processes altered by gestational PM exposure

\begin{tabular}{|c|c|c|c|c|c|c|c|c|}
\hline & \multicolumn{4}{|c|}{ Long-term } & \multicolumn{4}{|c|}{ Short-term } \\
\hline \multirow[b]{3}{*}{ Nervous system } & \multicolumn{2}{|c|}{ Girls } & \multicolumn{2}{|c|}{ Boys } & \multicolumn{2}{|c|}{ Girls } & \multicolumn{2}{|c|}{ Boys } \\
\hline & ORA & GSEA & ORA & GSEA & ORA & GSEA & ORA & GSEA \\
\hline & & SA & SA & & & SA & & SA \\
\hline \multicolumn{9}{|l|}{ Neurotransmission } \\
\hline \multirow{2}{*}{$\begin{array}{l}\text { Neurodevelopment } \\
\text { Olfactory }\end{array}$} & & & SA & & & & & \\
\hline & & SA & & & & SA & & SA \\
\hline \multirow[b]{2}{*}{ Cell cycle } & & SA & & SA & & SA & & SA \\
\hline & & & & $(\mathrm{SA}) \uparrow$ & & & & SA \\
\hline \multirow{2}{*}{$\begin{array}{l}\text { Ribosomal proteins } \\
\text { Histone proteins }\end{array}$} & & & & & & $(\mathrm{SA}) \uparrow$ & & SA \\
\hline & & SA & & & & & & \\
\hline \multirow{2}{*}{$\begin{array}{l}\text { RhoA } \\
\text { Mitochondrial } \\
\text { energy producing } \\
\text { processes }\end{array}$} & & & & & & & & SA \\
\hline & & & & & & & & SA \\
\hline \multicolumn{9}{|l|}{ Apoptosis } \\
\hline Protective response & SA & SA & SA & & SA & & & SA \\
\hline $\begin{array}{l}\text { DNA damage } \\
\text { response }\end{array}$ & SA & & SA & & SA & & & SA \\
\hline Defensins & & SA & & & & & & \\
\hline $\begin{array}{l}\text { Other immune } \\
\text { responses }\end{array}$ & SA & & SA & & SA & & & \\
\hline
\end{tabular}

ORA Overrepresentation Analysis. GSEA Gene Set Enrichment Analysis

Gray: $\mathrm{PM}_{2.5}$-related processes in the main analysis. SA: processes that remained significant in the sensitivity analysis. (SA) $\uparrow:$ most significant up-regulated pathways in the sensitivity analysis

originating from dividing cells that are formed by chromosomal breakage and/or whole chromosome loss [46]. A Danish birth cohort showed that micronuclei frequencies, measured in cord blood, were elevated among newborns whose mothers lived in high-traffic-density areas [47]. In our study, we identified several pathways that may underlie the carcinogenic potential of air pollution in early life. "ATM" and "BARD1" pathways were significantly modulated by $\mathrm{PM}_{2.5}$ exposure for short-term exposure in boys and long-term exposure in girls. These pathways play a central role in the response to DNA damage and may be important in the potential of $\mathrm{PM}_{2.5}$ to induce genotoxic stress. Jiang et al. found elevated ATM expression in esophageal squamous cell carcinoma specimens of smokers compared to non-smokers [48].

Other pathways related to DNA damage which were significantly associated with long-term $\mathrm{PM}_{2.5}$ exposure were "p73 transcription factor network", "Oncogen induced Senescence", and "TP53 network" in boys only. At the gene level the up-regulation of $M D M 2$, a negative regulator of TP53, is in line with the inverse association of long-term $\mathrm{PM}_{2.5}$ exposure and TP53 expression and its family member TP73. In contrast to our observations, Rossner et al. reported positive associations between p53 protein plasma levels and personal PAH exposure in city policemen and bus drivers at work [49].

Expression of these DNA damage responsive genes seem to be affected by $\mathrm{PM}_{2.5}$ exposure in a time dependent manner. It is plausible that deregulated gene expression of key players of the response to DNA damage, as a consequence of fine particle air pollution exposure, may increase the susceptibility to develop cancer and other diseases later in life.

The positive association between expression of gene members of the RhoA pathway, which are important for cytoskeleton organization, and gestational long- and short-term $\mathrm{PM}_{2.5}$ exposure for boys supports the idea that air pollution can activate the Rho/ROCK pathway $[50,51]$ potentially through increased production of reactive oxygen species (ROS) [52]. Our findings are consistent with those of Sun et al. who found increased expression levels of ROCK1 but not ROCK2 and RhoA, in aortic tissue of $\mathrm{PM}_{2.5}$-exposed rats compared with rats exposed to filtered air after they were infused with angiotensin II [51]. Along 
similar lines, evidence in aorta of mice indicated that the RhoA/ROCK pathway plays a fundamental role in $\mathrm{PM}_{2.5^{-}}$ mediated myocardial remodeling and hypertension [53].

Sex-specific pathways included "defensins" for girls. Most of the genes encoding defensin peptides were down-regulated with increasing long-term $\mathrm{PM}_{2.5}$ exposure. Defensins are host defense peptides with antibacterial activity and represent major components of innate immunity. Two subfamilies of defensins, $\alpha$ - and $\beta$-defensins, are present in humans: $\alpha$-defensins are mainly stored in granules of neutrophils and intestinal Paneth cells, while $\beta$-defensins are expressed in various epithelial cells. Interestingly, the gene expression of elastase (ELANE) and cathepsin G (CTSG, proteases interacting with precursors of $\alpha$-defensins [54]), were in the current study also significantly down-regulated and are members of the overrepresented "Urokinase-type plasminogen activator (uPA)" and "uPAR-mediated signaling pathway" (Table 2). Previous studies found a negative association between $\beta$-defensin gene expression and residential fly ash, one of the residues generated by oil combustion and being a potential component of $\mathrm{PM}_{2.5}$ $[55,56]$. Decreased levels of antimicrobial peptides, including defensins, may result in higher susceptibility to infections as observed in preterm neonates $[57,58]$.

For boys, several immune response pathways involved in both TNF-NF-KB (nuclear factor of kappa light polypeptide gene enhancer in B-cells) and $\mathrm{T}$ cell receptor signaling were associated with long-term $\mathrm{PM}_{2.5}$ exposure. After adjustment for blood cell count these pathways were no longer significant.

Mitochondria, the energy producers of the cells, are particularly sensitive to environmental toxicants due to their lack of DNA repair capacity. Fetuses may adapt their mitochondrial structure and function when the supply of nutrients is limited. Previously, we showed in the ENVIRONAGE birth cohort that placental mitochondrial DNA content [21] and epigenetic modifications [59] in the mitochondrial genome were associated with PM exposure during pregnancy. In line with these findings, we revealed that mitochondrial tricarboxylic acid cycle and respiratory electron chain pathways were significantly linked to short-term gestational $\mathrm{PM}_{2.5^{-}}$ exposure in boys.

The advantage of our study is that we used a standardized fine-scale exposure assessment enabling us to calculate both short- and long-term exposure on a high resolution scale. Exposure levels in our study were comparable with other European cohort studies. Our study has limitations. First, observational studies do not allow to establish causality. Second, the observed gene expression changes in umbilical cord blood are only indirect evidence of the effects on fetal target tissues such as cardiovascular and nervous tissue. We identified several $\mathrm{PM}_{2.5}$-altered genes involved in neural development. A review of 18 studies [60] evaluating comparability of peripheral blood and brain transcriptome data in adults estimated crosstissue correlation between 0.25 and 0.64 with stronger associations for some subsets of genes and biological processes. Novartis human transcriptomic data [61] showed the following median correlation coefficients between gene expression in whole blood and tissues: immune tissues $(R=0.64)$, central nervous system $(R=0.50)$, peripheral nervous system $(R=0.36)$, heart $(R=0.48)$, and fetal brain $(R=0.54)$. These results support to some extent the use of peripheral blood transcriptome data as surrogate for gene expression in other tissues such as the central nervous system [60, 61]. Maron et al. [62] identified fetal biomarkers by comparing gene expression profiles from both maternal and umbilical cord blood in humans. Interestingly, several of the identified transcripts present in both maternal and fetal circulation were identified to be affected by $\mathrm{PM}_{2.5}$ exposure in our study both in gene and pathway analysis. This includes immunological and olfactory receptor gene transcripts as well as genes important for development of the nervous system (see Tables 2 and 3 and Maron et al. [62]). Third, our study included 26 (18\%) smokers. We adjusted our analyses for maternal smoking status. Although smoking is a major source of personal air pollution exposure, it is unlikely that this biased the current results as we did not find a significant association between maternal smoking and residential air pollution levels. Lastly, the long-term $\mathrm{PM}_{2.5}$ concentration in our study ranged from 11.8 to $20.6 \mu \mathrm{g} /$ $\mathrm{m}^{3}$, with an interquartile range of $2.34 \mu \mathrm{g} / \mathrm{m}^{3}$. Although this exposure contrast is relatively narrow, previously even smaller contrasts in exposure has been reported in epidemiological studies studying hard clinical endpoints, e.g. the Worcester Heart Attack Study [63] reported a link with acute myocardial infarction for an interquartile range $\mathrm{PM}_{2.5}$ exposure contrast of $0.59 \mu \mathrm{g} / \mathrm{m}^{3}$. Nevertheless, we acknowledge that the small range of $\mathrm{PM}_{2.5}$ exposure and the large number of tests in combination with a small sample size reduces the power of our study. In this regard, we did not apply false discovery rate correction on the individual genes. To improve the reliability of our results, we focused on significant pathways and their genes instead of individual genes. We applied two approaches for the pathway analysis to fully understand the impact of prenatal $\mathrm{PM}_{2.5}$ exposure on gene expression: ORA which is based on the $p$-value of individual genes and GSEA which uses the fold change to identify significant pathways. GSEA does not require the use of a significance cutoff at gene level, thereby overcoming the issue of multiple testing. Although the low power of the current study due to the small range of $\mathrm{PM}_{2.5}$ exposure in the study region, we believe our study can serve as an exploratory analysis which may inspire further research in this area. 


\section{Conclusions}

To our knowledge, this is the first study showing a sexspecific link between gestational fine particles and whole genome gene expression in cord blood. The identified transcriptome pathways could provide new molecular insights as to the interaction pattern of early life $\mathrm{PM}_{2.5}$ exposure with the biological development of the fetus.

\section{Additional file}

\section{Additional file 1: Table S1. Descriptive characteristics of the} ENVIRONAGE birth cohort participants compared to all births in Flanders (Northern part of Belgium) from 2002 to 2011. Table S2. Significant differentially expressed genes by long-term $\mathrm{PM}_{2.5}$ exposure in cord blood of girls and boys. Table S3. Top ten significant genes in cord blood of newborn boys and girls associated with long-term PM $_{2.5}$ exposure. Table S4. Significant differentially expressed genes by short-term $\mathrm{PM}_{2.5}$ exposure in cord blood of girls and boys. Table S5. Top ten significant genes in cord blood of newborn boys and girls associated with short-term $\mathrm{PM}_{2.5}$ exposure. Figure $\mathbf{S}$ 1. Histogram representing the percentage of genes with $p$-value $<0.05$ for each variable included in the model. Figure S2. Principal component analysis plot showing the transcriptomic response to long- and short-term $P_{2.5}$ exposure in $(A, C)$ girls and $(B, D)$ boys. Figure S3. Pathways modulated by long-term $\mathrm{PM}_{2.5}$ exposure for girls $(A)$ and boys $(B)$ resulting from GSEA. Figure S4. Pathways modulated by short-term $\mathrm{PM}_{2.5}$ exposure for girls $(A)$ and boys $(B)$ resulting from GSEA. (DOCX $1749 \mathrm{~kb})$

\section{Abbreviations}

BMI: body mass index; Environage: ENVIRonmental influence ON early AGEing; FDR: false discovery rate; GO: gene ontology; GSEA: Gene Set Enrichment Analysis; IFDM: Immission Frequency Distribution Model; ORA: overrepresentation analysis; $\mathrm{PAH}$ : polycyclic aromatic hydrocarbons; PM: particulate matter; $\mathrm{PM}_{2.5}$ : particulate matter with a diameter $<2.5 \mu \mathrm{m}$; R: partial correlation coefficients; ROS: reactive oxygen species; SA: sensitivity analysis; SD: standard deviation; TCA: tricarboxylic acid; WBC: white blood cell

\section{Acknowledgements}

The authors thank the participating women, as well as the midwives and the staff of the clinical laboratory of East-Limburg Hospital in Genk.

\section{Funding}

This research is funded by the European Research Council (ERC-2012stG310898) and the Flemish Scientific Fund (FWO, G073315N). Ellen Winckelmans has a PhD. fellowship of Hasselt University (BOF program).

\section{Availability of data and materials}

The microarray data discussed in this publication have been deposited in NCBI's Gene Expression Omnibus [64] and are accessible through GEO Series accession number GSE83393 (http://www.ncbi.nlm.nih.gov/geo/ query/acc.cgi?acc=GSE83393).

\section{Authors' contributions}

TSN coordinates the ENVIRONAGE birth cohort and designed the current study together with EW and KV. BJ, NS and EW constructed the database. EW performed the statistical analysis and, with contribution of MT, the bioinformatical analysis. TMDK and JK were responsible for the transcriptome analysis. CP and WL did the air pollution modelling. EW wrote the first draft of the manuscript with the help of KV, HR and TSN. All authors were involved in data interpretation and critical revision of the manuscript. All authors read and approved the final manuscript.

\section{Competing interests}

The authors declare they have no competing financial interests.

\section{Consent for publication}

Not applicable.

\section{Ethics approval and consent to participate}

This study was approved by the Ethical Committee of Hasselt University and the East-Limburg Hospital (09/080 U;B37120107805), and complies with the Helsinki declaration. All participating mothers provided written informed consent.

\section{Publisher's Note}

Springer Nature remains neutral with regard to jurisdictional claims in published maps and institutional affiliations.

\section{Author details}

${ }^{1}$ Centre for Environmental Sciences, Hasselt University, Agoralaan gebouw D, B-3590 Diepenbeek, Belgium. ${ }^{2}$ Louvain Centre for Toxicology and Applied Pharmacology (LTAP), Université catholique de Louvain, Brussels, Belgium. ${ }^{3}$ Department of Toxicogenomics, Maastricht University, Maastricht, The Netherlands. ${ }^{4}$ Environmental Risk and Health, Flemish Institute for Technical Research (VITO), Mol, Belgium. ${ }^{5}$ Belgian Interregional Environment Agency (IRCEL), Brussels, Belgium. ${ }^{6}$ Department of Public Health \& Primary Care, Leuven University, Kapucijnenvoer 35, 3000 Leuven, Belgium.

Received: 20 February 2017 Accepted: 22 May 2017

Published online: 05 June 2017

\section{References}

1. Barker DJ. Fetal origins of coronary heart disease. BMJ. 1995;311:171-4.

2. Hochstenbach $K$, van Leeuwen DM, Gmuender H, Gottschalk RW, Lovik M, Granum B, et al. Global gene expression analysis in cord blood reveals gender-specific differences in response to carcinogenic exposure in utero. Cancer Epidemiol Biomark Prev. 2012;21:1756-67.

3. Nafee TM, Farrell WE, Carroll WD, Fryer AA, Ismail KM. Epigenetic control of fetal gene expression. BJOG. 2008;115:158-68.

4. Sram RJ, Binkova B, Dejmek J, Bobak M. Ambient air pollution and pregnancy outcomes: a review of the literature. Environ Health Perspect. 2005;113:375-82.

5. Shah PS, Balkhair T, Knowledge synthesis group on determinants of preterm LBWb. Air pollution and birth outcomes: a systematic review. Environ Int. 2011;37:498-516.

6. Winckelmans E, Cox B, Martens E, Fierens F, Nemery B, Nawrot TS. Fetal growth and maternal exposure to particulate air pollution - more marked effects at lower exposure and modification by gestational duration. Environ Res. 2015;140:611-8.

7. Rappazzo KM, Daniels JL, Messer LC, Poole C, Lobdell DT. Exposure to fine particulate matter during pregnancy and risk of preterm birth among women in New Jersey, Ohio, and Pennsylvania, 2000-2005. Environ Health Perspect. 2014;122:992-7.

8. Chang HH, Warren JL, Darrow LA, Reich BJ, Waller LA. Assessment of critical exposure and outcome windows in time-to-event analysis with application to air pollution and preterm birth study. Biostatistics. 2015;16:509-21.

9. van Rossem L, Rifas-Shiman SL, Melly SJ, Kloog I, Luttmann-Gibson H, Zanobetti $A$, et al. Prenatal air pollution exposure and newborn blood pressure. Environ Health Perspect. 2015;123:353-9.

10. Wick P, Malek A, Manser P, Meili D, Maeder-Althaus X, Diener L, et al. Barrier capacity of human placenta for nanosized materials. Environ Health Perspect. 2010;1 18:432-6.

11. Perera FP, Tang D, Wang S, Vishnevetsky J, Zhang B, Diaz D, et al. Prenatal polycyclic aromatic hydrocarbon (PAH) exposure and child behavior at age 6-7 years. Environ Health Perspect. 2012;120:921-6.

12. Peterson BS, Rauh VA, Bansal R, Hao X, Toth Z, Nati G, et al. Effects of prenatal exposure to air pollutants (polycyclic aromatic hydrocarbons) on the development of brain white matter, cognition, and behavior in later childhood. JAMA Psychiatry. 2015;72:531-40.

13. Heck JE, Wu J, Lombardi C, Qiu J, Meyers TJ, Wilhelm M, et al. Childhood cancer and traffic-related air pollution exposure in pregnancy and early life. Environ Health Perspect. 2013;121:1385-91.

14. Ghosh JK, Heck JE, Cockburn M, Su J, Jerrett M, Ritz B. Prenatal exposure to traffic-related air pollution and risk of early childhood cancers. Am J Epidemiol. 2013;178:1233-9.

15. Vieira SE. The health burden of pollution: the impact of prenatal exposure to air pollutants. Int J Chron Obstruct Pulmon Dis. 2015;10:1111-21. 
16. Morales E, Garcia-Esteban R, de la Cruz OA, Basterrechea M, Lertxundi A, de Dicastillo MD, et al. Intrauterine and early postnatal exposure to outdoor air pollution and lung function at preschool age. Thorax. 2015;70:64-73.

17. Ghosh R, Rankin J, Pless-Mulloli T, Glinianaia S. Does the effect of air pollution on pregnancy outcomes differ by gender? A systematic review. Environ Res. 2007;105:400-8.

18. Roberts AL, Lyall K, Hart JE, Laden F, Just AC, Bobb JF, et al. Perinatal air pollutant exposures and autism spectrum disorder in the children of Nurses' health study II participants. Environ Health Perspect. 2013;121:978-84.

19. Penaloza C, Estevez B, Orlanski S, Sikorska M, Walker R, Smith C, et al. Sex of the cell dictates its response: differential gene expression and sensitivity to cell death inducing stress in male and female cells. FASEB J. 2009;23:1869-79.

20. Warembourg C, Debost-Legrand A, Bonvallot N, Massart C, Garlantezec R, Monfort $C$, et al. Exposure of pregnant women to persistent organic pollutants and cord sex hormone levels. Hum Reprod. 2016;31:190-8.

21. Janssen BG, Munters E, Pieters N, Smeets K, Cox B, Cuypers A, et al. Placental mitochondrial DNA content and particulate air pollution during in utero life. Environ Health Perspect. 2012;120:1346-52.

22. Lefebvre W, Vercauteren J, Schrooten L, Janssen S, Degraeuwe B, Maenhaut W, et al. Validation of the MIMOSA-AURORA-IFDM model chain for policy support: modeling concentrations of elemental carbon in Flanders. Atmos Environ. 2011:45:6705-13

23. Lefebvre W, Degrawe B, Beckx C, Vanhulsel M, Kochan B, Bellemans T, et al. Presentation and evaluation of an integrated model chain to respond to traffic- and health-related policy questions. Environ Model Softw. 2013; 40:160-70.

24. Maiheu B, Veldeman B, Viaene P, De Ridde rK, Lauwaet D, Smeets $N$ et al. Identifying the best available large-scale concentration maps for air quality in Belgium. 2012. http://www.milieurapport.be/Upload/main/0_ onderzoeksrapporten/2013/Eindrapport_Concentratiekaarten_29_01_2013_ TW.pdf. Accessed 14 Dec 2015.

25. Dopico XC, Evangelou M, Ferreira RC, Guo H, Pekalski ML, Smyth DJ, et al. Widespread seasonal gene expression reveals annual differences in human immunity and physiology. Nat Commun. 2015;6:7000

26. Johnson WE, Li C, Rabinovic A. Adjusting batch effects in microarray expression data using empirical Bayes methods. Biostatistics. 2007:8:118-27.

27. Imanishi S, Manabe N, Nishizawa H, Morita M, Sugimoto M, Iwahori M, et al. Effects of oral exposure of bisphenol a on mRNA expression of nuclear receptors in murine placentae assessed by DNA microarray. J Reprod Dev. 2003;49:329-36.

28. Van den Hove DL, Kenis G, Brass A, Opstelten R, Rutten BP, Bruschettini M, et al. Vulnerability versus resilience to prenatal stress in male and female rats; implications from gene expression profiles in the hippocampus and frontal cortex. Eur Neuropsychopharmacol. 2013;23:1226-46.

29. Jackson P, Hougaard KS, Vogel U, Wu D, Casavant L, Williams A, et al. Exposure of pregnant mice to carbon black by intratracheal instillation: toxicogenomic effects in dams and offspring. Mutat Res. 2012;745:73-83.

30. Jackson P, Halappanavar S, Hougaard KS, Williams A, Madsen AM, Lamson JS, et al. Maternal inhalation of surface-coated nanosized titanium dioxide (UV-titan) in C57BL/6 mice: effects in prenatally exposed offspring on hepatic DNA damage and gene expression. Nanotoxicology. 2013;7:85-96.

31. Kamburov A, Pentchev K, Galicka H, Wierling C, Lehrach H, Herwig R. ConsensusPathDB: toward a more complete picture of cell biology. Nucleic Acids Res. 2011;39:D712-7.

32. Mootha VK, Lindgren CM, Eriksson KF, Subramanian A, Sihag S, Lehar J, et al. PGC-1alpha-responsive genes involved in oxidative phosphorylation are coordinately downregulated in human diabetes. Nat Genet. 2003;34:267-73.

33. Subramanian A, Tamayo P, Mootha VK, Mukherjee S, Ebert BL, Gillette MA, et al. Gene set enrichment analysis: a knowledge-based approach for interpreting genome-wide expression profiles. Proc Natl Acad Sci U S A. 2005;102:15545-50.

34. Cline MS, Smoot M, Cerami E, Kuchinsky A, Landys N, Workman C, et al. Integration of biological networks and gene expression data using Cytoscape. Nat Protoc. 2007;2:2366-82.

35. Bruske I, Hampel R, Socher MM, Ruckerl R, Schneider A, Heinrich J, et al. Impact of ambient air pollution on the differential white blood cell count in patients with chronic pulmonary disease. Inhal Toxicol. 2010;22:245-52.

36. Steenhof M, Janssen NA, Strak M, Hoek G, Gosens I, Mudway IS, et al. Air pollution exposure affects circulating white blood cell counts in healthy subjects: the role of particle composition, oxidative potential and gaseous pollutants - the RAPTES project. Inhal Toxicol. 2014;26:141-65.
37. Genc S, Zadeoglulari Z, Fuss SH, Genc K. The adverse effects of air pollution on the nervous system. J Toxicol. 2012;2012:782462.

38. Zhao W, Ho L, Varghese M, Yemul S, Dams-O'Connor K, Gordon W, et al. Decreased level of olfactory receptors in blood cells following traumatic brain injury and potential association with tauopathy. J Alzheimers Dis. 2013;34:417-29.

39. Brown LA, Khousbouei H, Goodwin JS, Irvin-Wilson CV, Ramesh A, Sheng $L$, et al. Down-regulation of early ionotrophic glutamate receptor subunit developmental expression as a mechanism for observed plasticity deficits following gestational exposure to benzo(a)pyrene. Neurotoxicology. 2007:28:965-78

40. Li SP, Park MS, Bahk JY, Kim MO. Chronic nicotine and smoking exposure decreases $\mathrm{GABA}(\mathrm{B} 1)$ receptor expression in the rat hippocampus. Neurosci Lett. 2002;334:135-9.

41. Xu Y, Yan J, Zhou P, Li J, Gao H, Xia Y, et al. Neurotransmitter receptors and cognitive dysfunction in Alzheimer's disease and Parkinson's disease. Prog Neurobiol. 2012:97:1-13.

42. Moorthy B, Chu C, Carlin DJ. Polycyclic aromatic hydrocarbons: from metabolism to lung cancer. Toxicol Sci. 2015:145:5-15.

43. Nawrot T, Plusquin M, Hogervorst J, Roels HA, Celis H, Thijs L, et al. Environmental exposure to cadmium and risk of cancer: a prospective population-based study. Lancet Oncol. 2006;7:119-26.

44. Selevan SG, Kimmel CA, Mendola P. Identifying critical windows of exposure for children's health. Environ Health Perspect. 2000;108(Suppl 3):451-5.

45. Wright $\mathrm{RO}$, Christiani D. Gene-environment interaction and children's health and development. Curr Opin Pediatr. 2010;22:197-201.

46. Bonassi S, Znaor A, Ceppi M, Lando C, Chang WP, Holland N, et al. An increased micronucleus frequency in peripheral blood lymphocytes predicts the risk of cancer in humans. Carcinogenesis. 2007;28:625-31.

47. Pedersen M, Wichmann J, Autrup H, Dang DA, Decordier I, Hvidberg M, et al. Increased micronuclei and bulky DNA adducts in cord blood after maternal exposures to traffic-related air pollution. Environ Res. 2009;109:1012-20.

48. Jiang $Y$, Liang ZD, Wu T, Cao L, Zhang H, Xu XC. Ataxia-telangiectasia mutated expression is associated with tobacco smoke exposure in esophageal cancer tissues and benzo[a]pyrene diol epoxide in cell lines. Int J Cancer. 2007;120:91-5.

49. Rossner P Jr, Binkova B, Milcova A, Solansky I, Zidzik J, Lyubomirova KD, et al. Air pollution by carcinogenic PAHs and plasma levels of p53 and p21(WAF1) proteins. Mutat Res. 2007:620:34-40.

50. Kim JS, Kim JG, Jeon CY, Won HY, Moon MY, Seo JY, et al. Downstream components of RhoA required for signal pathway of superoxide formation during phagocytosis of serum opsonized zymosans in macrophages. Exp Mol Med. 2005:37:575-87.

51. Sun $Q$, Yue $P$, Ying Z, Cardounel AJ, Brook RD, Devlin R, et al. Air pollution exposure potentiates hypertension through reactive oxygen species-mediated activation of rho/ROCK. Arterioscler Thromb Vasc Biol. 2008:28:1760-6.

52. Lodovici M, Bigagli E. Oxidative stress and air pollution exposure. J Toxicol. 2011:2011:487074.

53. Ying Z, Yue $P, X u$ X, Zhong M, Sun Q, Mikolaj M, et al. Air pollution and cardiac remodeling: a role for RhoA/rho-kinase. Am J Physiol Heart Circ Physiol. 2009;296:H1540-50.

54. Tongaonkar P, Golji AE, Tran P, Ouellette AJ, Selsted ME. High fidelity processing and activation of the human alpha-defensin HNP1 precursor by neutrophil elastase and proteinase 3. PLoS One. 2012;7:e32469.

55. Hatch GE, Boykin E, Graham JA, Lewtas J, Pott F, Loud K, et al. Inhalable particles and pulmonary host defense: in vivo and in vitro effects of ambient air and combustion particles. Environ Res. 1985;36:67-80.

56. Klein-Patel ME, Diamond G, Boniotto M, Saad S, Ryan LK. Inhibition of betadefensin gene expression in airway epithelial cells by low doses of residual oil fly ash is mediated by vanadium. Toxicol Sci. 2006;92:115-25.

57. Starner TD, Agerberth B, Gudmundsson GH, McCray PB Jr. Expression and activity of beta-defensins and LL-37 in the developing human lung. J Immunol. 2005;174:1608-15.

58. Olbrich P, Pavon A, Rosso ML, Molinos A, de Felipe B, Sanchez B, et al. Association of human beta-defensin-2 serum levels and sepsis in preterm neonates*. Pediatr Crit Care Med. 2013;14:796-800.

59. Janssen BG, Byun HM, Gyselaers W, Lefebvre W, Baccarelli AA, Nawrot TS. Placental mitochondrial methylation and exposure to airborne particulate matter in the early life environment: an ENVIRONAGE birth cohort study. Epigenetics. 2015;10:536-44. 
60. Tylee DS, Kawaguchi DM, Glatt SJ. On the outside, looking in: a review and evaluation of the comparability of blood and brain "-omes". Am J Med Genet B Neuropsychiatr Genet. 2013;162B:595-603.

61. Sullivan PF, Fan C, Perou CM. Evaluating the comparability of gene expression in blood and brain. Am J Med Genet B Neuropsychiatr Genet. 2006;141B:261-8.

62. Maron JL, Johnson KL, Slonim D, Lai CQ, Ramoni M, Alterovitz G, et al. Gene expression analysis in pregnant women and their infants identifies unique fetal biomarkers that circulate in maternal blood. J Clin Invest. 2007;117:3007-19.

63. Madrigano J, Kloog I, Goldberg R, Coull BA, Mittleman MA, Schwartz J. Long-term exposure to PM2.5 and incidence of acute myocardial infarction. Environ Health Perspect. 2013;121:192-6.

64. Edgar R, Domrachev M, Lash AE. Gene expression omnibus: NCBI gene expression and hybridization array data repository. Nucleic Acids Res. 2002;30:207-10.

Submit your next manuscript to BioMed Central and we will help you at every step:

- We accept pre-submission inquiries

- Our selector tool helps you to find the most relevant journal

- We provide round the clock customer support

- Convenient online submission

- Thorough peer review

- Inclusion in PubMed and all major indexing services

- Maximum visibility for your research

Submit your manuscript at www.biomedcentral.com/submit 